\title{
Design Directed Engineering Education
}

\author{
Ian Yellowley*, Peihua $\mathrm{Gu}^{* *}$ \\ *Department of Mechanical Engineering, University of British Columbia \\ **Department of Mechanical and Manufacturing Engineering, University of Calgary \\ yellowley@mech.ubc.ca
}

\begin{abstract}
The authors examine the changes and opportunities in the educational environment that will occur as packaged courseware and virtual access to laboratories are assimilated into the engineering curriculum worldwide. The impact on Universities and in turn on Canadian industry will be major unless there is a coordinated effort that can turn the challenge into an opportunity. The opportunity, the authors believe, is to use this new material to allow innovative approaches to education that use Design to direct student learning. The major benefits would be a greater appreciation of technology and practice and significantly improved communication skills, (both of which are regarded as essential by industrial employers). The authors believe that the engineering science background would be enhanced rather than weakened by the approach suggested.
\end{abstract}

\subsection{Introduction}

The Canadian economy is becoming increasingly knowledge-based and activities knowledge-intensive. This is true of most industrial nations; rapid technological advance is required to remain competitive. For Canada the situation is made more difficult by the fact the country is in the process of moving away from a resource based economy. The response to the problem has to be improved education and skills and Canadian Industry has clearly recognized the need for continuous professional development. The question for Universities is what sort of engineering or technological education do we need to stay abreast in a world which is changing rapidly and where a knowledge of the basic engineering skills is extremely widespread? Engineering education in Canada must become more responsive and progressive, it has to provide engineers who are well qualified in the traditional sense, but to compete on the international scene this is clearly not nearly enough.

Canadian universities, in common with all others will soon see a rapidly increasing rate of change in the environment in which they try to educate the next generations. The internet and electronic media in general will drive this change. Programs, curricula and detailed course materials are widely available on the Internet and of course access to physical experiments and the development of ever better simulation tools coupled with internet enabled physical plant will allow extremely high class traditional tools to be available to all worldwide at very low cost. Various high profile initiatives are underway especially in

the USA to make the best of courseware available on the Internet, free of charge. It is very clear that 5 years from now most, if not all, of the traditional materials and classic tutorial, laboratory or problem based approaches within traditional engineering programs will be widely and cheaply available. Each one of the Engineering Schools then needs to ask the question now as to what real value we as educators can add to this material? Each university and each level of government needs to be asking what needs to be done, where are the critical shortcomings, and what will be the economic result to all of us. As a hint it is unlikely that building more real estate within the Universities is a good idea when students need reduced access to traditional contacts through lecture or tutorial or laboratory. The idea of simply adding more faculty is also an unlikely solution to the challenge.

The authors believe that radical change is required if students are to be innovative enough to help Canadian industry survive in the world climate they will find upon graduation. There is not enough time following graduation nor are there significant opportunities for these students to assimilate the technologies underlying the products they will be designing, using or competing with. Typically they will not have been exposed to many of the so-called soft but very important skills they need to be productive. Few large companies still have the training programs of old. The typical new company is smaller and leaner, they do not have the training resources, (nor the luxury to allow several years of learning).

\subsection{Engineering Program and Curriculum}

Engineering competencies are regulated and controlled through engineering accreditation. According to the Canadian Engineering Accreditation Board (CAEB), engineering competencies in engineering programs are divided into five components: mathematics, basic sciences, engineering sciences, engineering design and complementary studies. A typical engineering program, such as mechanical engineering, has 1 to 2 years of common core engineering courses followed by 2 to 3 years of mechanical engineering courses, plus complementary studies. The sequences of courses are controlled through 
prerequisites to ensure that students have a sufficient background to learn the course content. A typical engineering science course normally consists of lectures, laboratories and tutorials. Students are usually required to do assignments and projects to help them digest the learned materials. Evaluations may include assignments, laboratory reports, project reports, quizzes and exams. Most universities offer a design project course to expose students to real-world industrial or research projects.

Curriculum changes and controls have well-established processes and procedures to ensure that any proposed changes are evaluated and discussed thoroughly. The process is initiated by individual instructors or subject area committees, and proceeds through the Departments and Faculties. Incremental changes are normally carried out on a regular basis by individual instructors, since they have the most control of course content. Major changes must go through the formal process. If course instructors teach the same courses for a long time, course materials may not be changed making the course content stable. On the other hand, course content must be current; a lack of updated material may be undesirable.

Through the years of engineering education evolution and the exchanges among engineering schools through various forms, it is most likely that well-established disciplines in some engineering programs at Canadian universities are fundamentally similar. (There are some enlightened schools who have taken a much more radical and sensible approach, (3)). Delivery modes are also alike. The only major differences may be the quality of students, the competency of instructors and the learning environment, which includes support staff and materials, as well as laboratory facilities.

Design is generally regarded as the correct vehicle to integrate the various engineering and related courses. Many, if not most, schools have a real capstone design project, but relatively few have ongoing both open and simpler heavily constrained design exercises. Figure 1 shows an example of an integrated engineering curriculum using design problems and specific design projects that would provide students with the opportunity to practise both technical and nontechnical knowledge and skills in creating innovation (new designs or engineering solutions). A few schools in North America do have such a continuous process, (and have had for a while), e.g. (3), (4).

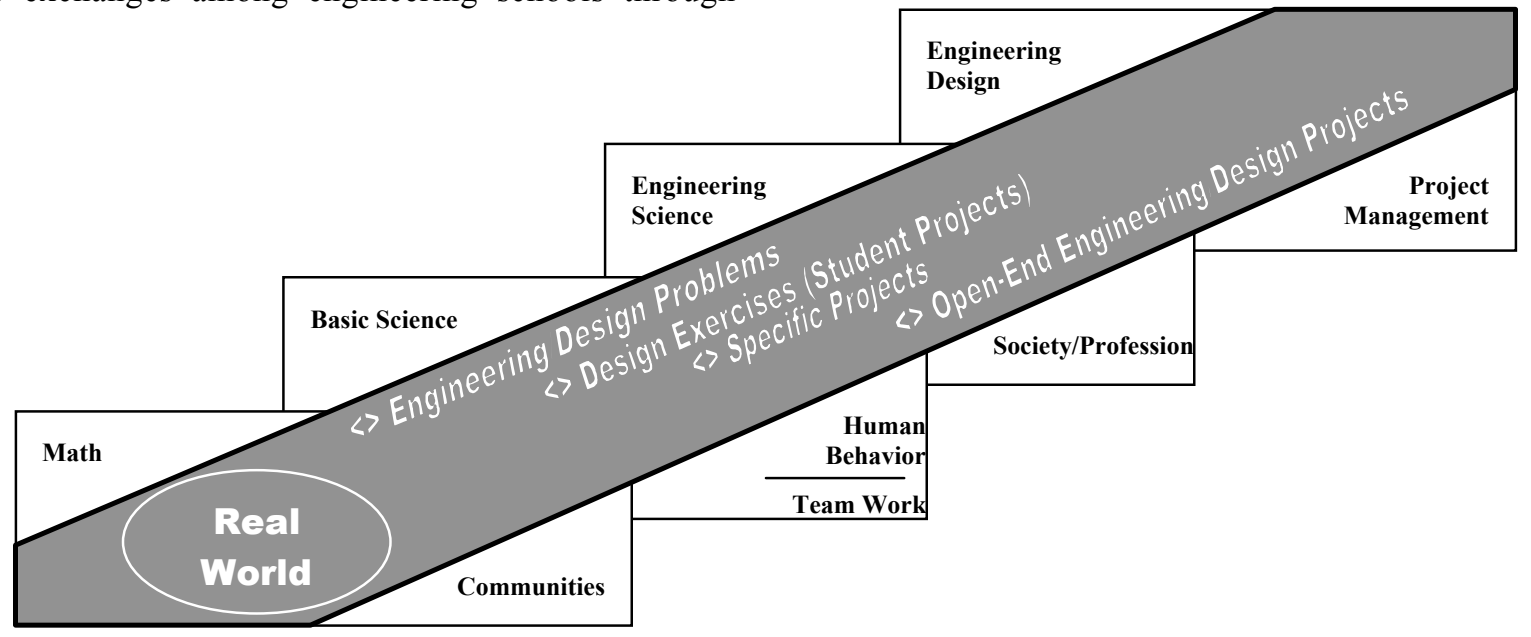

Figure 1. Integration of Engineering Curriculum Using Design Engineering

\subsection{The Industrial (User) Viewpoint}

The viewpoint portrayed results from an industrial workshop held with participants from several industrial sectors: engineering procurement and construction (EPC), oil and gas, engineering consulting, high-tech, manufacturing, and management consultants. The workshop took place in (2003) in Calgary Alberta. Participants were asked to provide input on the competencies that graduating engineering students should possess with respect to engineering design activities.
Because of limited space, the following high-level competencies were identified as those that a new engineer-in-training (EIT) should have first day on the job.

\section{Scientific and Technical Knowledge}

- knowledge of mathematics, basic sciences, engineering sciences and engineering design and practices

- $\quad$ specific knowledge pertinent to an engineering discipline (i.e. mechanical or electrical engineering) 
- technical risk management

Process/Methodology

- design process and methodologies

- design and analysis tools

- $\quad$ problem-solving skills

- data acquisition, analysis and interpretation

- application of scientific principles to identification and solution of practical engineering problems

\section{Creativity/Innovation}

- demonstration of knowledge and skill in design as a creative, iterative and open-ended process

- knowledge and application of idea generation and selection techniques

- $\quad$ understanding of the concept of problem and solution domains

\section{Team/Interpersonal/Personal}

- team skills, cross-functional teams, team dynamics, "service" work ethic, customer focus

- diversity, equity, personal ethics, integrity, humility

\section{Project and Engineering Management}

- time management, budgets, design to cost

- $\quad$ planning, estimating, scheduling

- management of facilities and processes

- management of human resources

Communications

- understanding of effective communication

- $\quad$ effective verbal, written and visual communication skills

- $\quad$ effective presentations

\section{Professional Practice}

- professional ethics, product liability, intellectual property, legal considerations

- role of the engineer in society

- technology and society

- $\quad$ sustainable design (lifecycle approach)

\section{General Feedback}

- The University can't hope to change students' behaviour but can create awareness in many key areas. Instructors can set expectations and provide feedback (e.g. $360^{\circ}$ feedback, where students are evaluated by themselves, instructors and peers) as well as provide coping tools when warranted.

- The Faculty needs to weave team building skills, organizational skills, etc. into the program much earlier. It is not sufficient to provide students with "one big dose" through design projects in their fourth year.

- Students need to be aware that life-long learning is critical. Professional associations such as the Association of Engineers, Geologists and Geophysicists of Alberta (APEGGA) help to promote this view.
- Students need to be reminded that some of what they are learning now will not become relevant for a few years. For example, projects are conducted like a mini-company with students being responsible for all aspects of the project. Many of these aspects would not fall under the responsibility of an EIT.

\section{Work Experience}

- Students should be encouraged to take advantage of opportunities for internship/co-op placements. Historically, engineering students could often find summer work related to their engineering field but, in general, this is no longer the case. If internship or co-op placement aren't options, students should be encouraged to seek out volunteer opportunities through which they can learn and develop their skills.

- Students are often unaware of the opportunities available in various industries. Hopefully, an internship program can help identify the diversity of industries and related opportunities.

- Internship students and EITs seem to avoid "backwoods" assignments in favour of a downtown office tower. The participants stressed that the students/graduates who take advantage of these "backwoods" assignments tend to be better off in the long run.

- Students should be made aware of what a mentor is and how to find a mentor when they are in industry (either on internship or as an EIT).

Industry Representation/Participation

- At least some of the instructors within each engineering department should have significant industry experience so that they can relate the theory back to industry examples.

- Real-life projects involving people from industry will provide students with realistic feedback and increase their experience with practical business skills.

Following this workshop, an academic workshop was held with faculty members from all the engineering disciplines from the Faculty of Engineering at the University of Calgary. The workshop identified the gaps between industrial needs and the competencies provided by the current engineering programs..

This table is just a fraction of the competency matrix, but it demonstrates how the technical competencies are acquired through a 4-year engineering education. It is, by no means, complete. A more comprehensive and detailed design engineering competency matrix has been developed by the NSERC Design Chair group (Stuart et al., 2004). The point of the exercise is to force the providers of the solution, (the Universities), with the requirements of the user, (the Engineering Industry or society as a whole). 


\begin{tabular}{|c|c|c|c|c|c|}
\hline 1. & Technical & $1^{\text {st }} \mathrm{yr}$ & $2^{\text {nd }} y r$ & $3^{\text {rd }} \mathrm{yr}$ & $4^{\text {th }} y r$ \\
\hline$\circ$ & $\begin{array}{l}\text { perform design and/or analyse functions of limited scope and complexity } \\
\text { (e.g., create detailed design from preliminary design) }\end{array}$ & I & I & I & $P$ \\
\hline$\circ$ & $\begin{array}{l}\text { demonstrate substantial knowledge of technical subjects pertinent to } \\
\text { their disci pline }\end{array}$ & I & $P$ & $P$ & $\mathrm{P} / \mathrm{S}$ \\
\hline & ? knowledge of Mathematics fundamentals & I & $P$ & S & $S$ \\
\hline & ? knowledge of Basic Sciences & I & $P$ & $P$ & S \\
\hline & $\begin{array}{l}\text { knowledge and skills in the area of Engineering Science and } \\
\text { Engineering Design }\end{array}$ & I & I & $P$ & $P$ \\
\hline & ? solid grasp of engineering fundamentals & I & $P$ & $P$ & S \\
\hline$\circ$ & understanding technical requirement s (purpose, good vs. bad) & I & I & $P$ & $P$ \\
\hline$\circ$ & $\begin{array}{l}\text { build work products from specifications including prototypes for design } \\
\text { proving }\end{array}$ & I & I & $P$ & $P$ \\
\hline$\circ$ & use design debug techniques and tools & I & I & $P$ & $P$ \\
\hline$\circ$ & $\begin{array}{l}\text { demonstrate a basic understanding of simulation and modelling of } \\
\text { products and systems }\end{array}$ & & I & I & $P$ \\
\hline$\circ$ & $\begin{array}{l}\text { understand component } \& \text { material selection and use design } \\
\text { layout/development tools }\end{array}$ & & I & I & $P$ \\
\hline$\circ$ & document the design implementation in clear concise terms & I & I & $P$ & S \\
\hline
\end{tabular}

\section{Table 1 COMPETENCY MATRIX (an excerpt)} I - Introduction, P - Primary Focus, S - Supporting

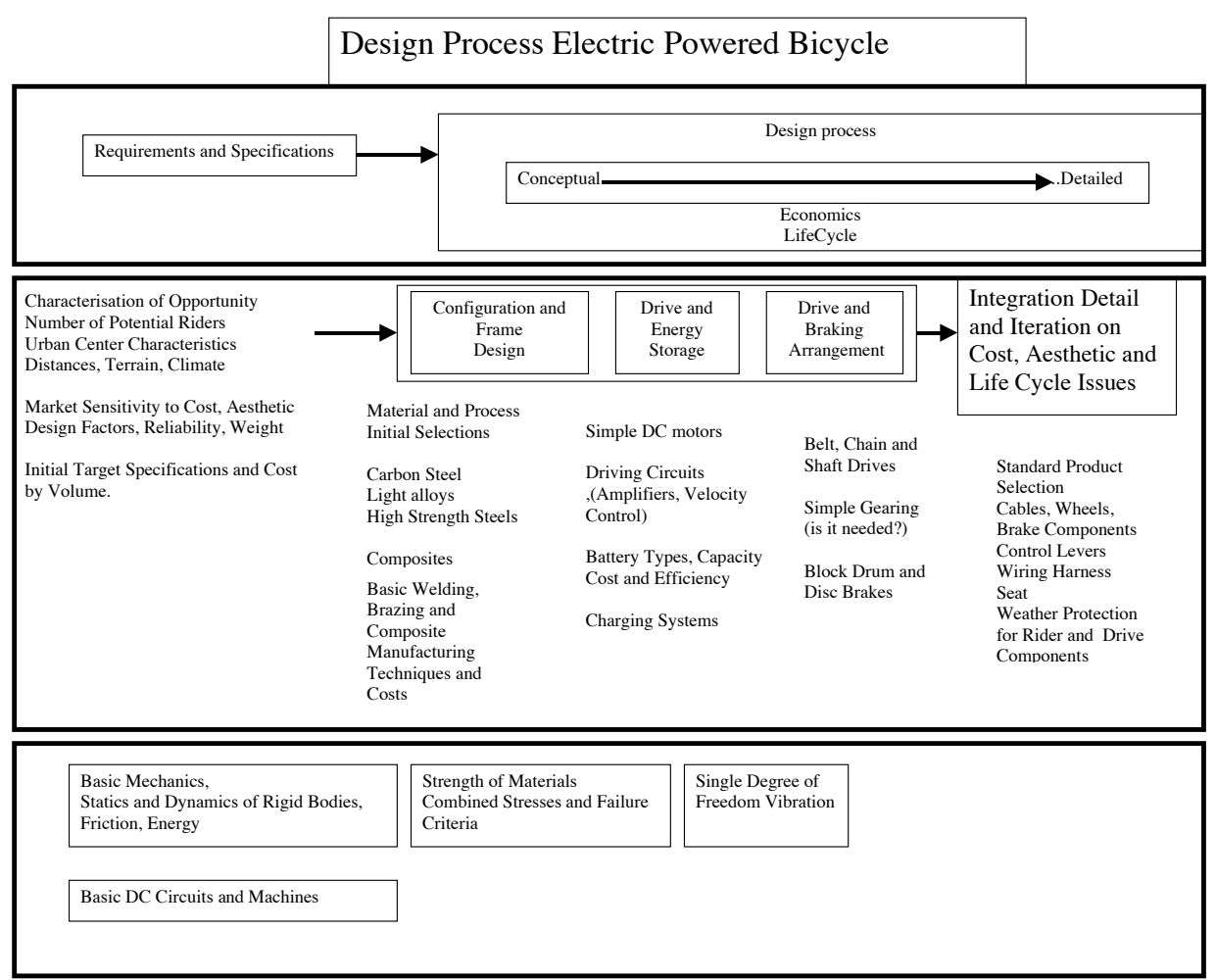

Figure 2. Technology and Practice within a Simple Design Exercise 


\subsection{Design Directed Engineering Education}

The previous sections have indicated that traditional engineering programs are very uniform (and one has to admit directed most clearly towards the needs of the student heading towards Graduate Studies or research rather than to a career in innovative engineering practice). Given industry needs now as briefly indicated, and the fundamental changes one might expect to see in the infrastructures available to education worldwide, there are very considerable challenges and the need it seems for radical change. This is particularly the case for a large proportion of the students who see their career as being directed towards the design of new products, processes or systems. (This may be approximately $30 \%$ of the typical student population in engineering with a large group headed to management or business and a smaller contingent to research).

The authors believe there is an opportunity to benefit greatly from the changes occurring by using the improvement in accessibility to engineering science, not to teach engineering science in a traditional environment, but to use the presence of this material (within the design environment) to aid the exposure of students to the technology and practice of engineering through a Design Directed as opposed to traditional or Problem Based Learning approaches. This is enabled by the changes in infrastructure and provides a route to a much richer education, as well as a redefined role for faculty and facilities. The authors believe that it is not enough to introduce engineering students to open format design problems, these problems should expose students to large bodies of specialized practice and technology that is found in all advanced technological fields. At the same time the student must learn to work as a member of a team and develop communication skills to interact with colleagues and characterize their work. Engineering Science forms a framework for the efficient use and appraisal of this knowledge; but is not alone sufficient for the development of such technology or to make sensible decisions regarding utilization, (without experience). The student exposed to engineering practice and technology over a wide range of sectors will also of necessity need to be introduced to Engineering Science in a rigorous manner, the reverse is not the case, a large number of our students have little or no 'engineering appreciation'. The best analogy is perhaps to think of the technology and practice as the vocabulary of engineering, to think of the design process as composition and to think of engineering science as the grammar.

Figure (2) below shows the technology and practice clusters that can be profitably addressed in a very simple student design exercise concerned with the design of an electric powered bicycle. The exercise is such that $2^{\text {nd }}$ year mechanical or electro-mechanical students will be easily capable of understanding all the basic science. The volume of technology though is large and requires explanation using additional engineering science. Several of the decisions (frame type, drive arrangement etc) need to be posed in a very general manner. The student should not be encouraged to perform detailed engineering analysis until the main conceptual options have been explored technically and economically to prune the solution space. (This should be done by the students themselves). The students will profit from analogies and examples of practice from related fields, for example in examining the frame design one might want to look at typical light weight structures from the aircraft, marine and building fields to stimulate thinking about innovative solutions. The drive system should be illustrated by examining light vehicles, golf carts and other related applications. To look at one solution may encourage duplication, to examine multiple very different solutions encourages analysis and innovation.

The use of design to encourage students to explore technology and practice and in turn to rigorously analyse possible solutions from technical, economic, and use perspectives is extremely appealing. One might ask if this type of activity could be a substitute for the traditional engineering education? The authors believe that this is certainly the case in theory, but there are several background issues that need to be carefully addressed. The first is the need to confirm that the design exercises posed are exhaustive in their coverage of the basic engineering science. The second is to confirm that the student retains a 'hands on' access to basic laboratories or even better that component testing related to individual design exercises covers the materials that would normally be covered in laboratories.

The idea of such a program is rather new and to now it has been very hard to persuade colleagues to take such steps. Clearly the changes being thrust upon us may change this. One of the authors, (IY), has proposed an Undergraduate Product Design Program that would be accommodated within a Design Studio Environment at UBC, (the proposed facility would also be utilized for a joint Industry/University masters level program in Product and Process Design). It should be emphasized that after many years this is still not a reality; to this point there is not the critical mass within the faculty that would embrace such an initiative. The intention within this paper is to simply use this idea as a model of what might be common in the relatively near future.

The typical student day in such programs would be divided as shown in table (2). It is seen that the teaching function disappears in favor of first self-study, then rapid examination in terms of tutorials and problem sets then rapid use within design exercises. The faculty requirements are a little higher than within a typical lecture program, and the background required of the faculty is expected to be very different than one might prescribe for lecture courses only. 


\begin{tabular}{|l|l|l|l|l|}
\hline $8.00-10.00$ & $10.00-12.30$ & $1.30-2.30$ & $2.30-4.30$ & $6.00-?$ \\
\hline $\begin{array}{l}\text { Complimentary } \\
\text { Coursework } \\
\text { (Liberal studies, } \\
\text { economics, law, etc) }\end{array}$ & Personal study in Design Studio & Office hours and tutorials & Design Studio & \\
Problem sets done here & (Mandatory) & 2/4 afternoons & \\
\end{tabular}

\section{TABLE (2), Typical Daily $2^{\text {nd }}$ and $3^{\text {rd }}$ Year Schedule}

Without formal classes in the basic subjects, there will be a fair need for ongoing student support. TA's could be used to support groups of up to 6 students, say one hour per week per subject. Faculty would also have office hours and students be allowed to make appointments, (perhaps 5 hours per week total). The major reinforcement is intended to come from the problem sets and the design exercises. The design of the actual set of design problems to be used each year is the most challenging part of the curriculum design. A discussion follows.

The design exercises would be carried out in a studio environment, each student being provided with space and access to a design station which is also running a browser that has access to all basic engineering science materials as well as design catalog material etc. One needs to design for each year of the program a set of challenging design problems that are exhaustive in their coverage of the science in the parallel coursework. Likely this needs a large number of faculty with varied experience to do this. A reasonable approach with small numbers of students (30 maximum), would be to have 6 different faculty design specific standard projects and have a single faculty with responsibility for overall course supervision. The typical standard project at the $2^{\text {nd }}$ and $3^{\text {rd }}$ year levels would last for four weeks with a single faculty supervising. In $2^{\text {nd }}$ and $3^{\text {rd }}$ years, at least one major design project per year would require the students to work in teams over the full year and to both build and test a prototype of their design. Final year would see the regular Capstone Design project in addition and a reduction of laboratory activity in favor of fabrication and test of design components.

\subsection{Development of Design Teaching Materials}

The types of program being suggested will benefit greatly from the presence of improved course materials in the traditional areas. This material is appearing at an ever increasing rate. There is still the need to develop modular teaching materials that cover the other areas of practice and technology, and puts these areas, together with Engineering Science, into a design context. Some schools have started this but it is not an easy task and cannot be really designed, developed and maintained by any one school in the Canadian context. The approach then has been to try to form a network that would develop and share these resources for the benefit of all. The result of this was the formation of CDEN/RCCI network whose aims at the time were communicated as follows:

"The CDEN/RCCI network is intended to enable the communication of best design practices between schools, promote the production and sharing of courseware, help inject more real design experiences into the university, and allow all schools to access the best available expertise in areas of detailed interest. The network will facilitate the joint development of multi-discipline design related courseware modules and put in place the mechanisms to ensure that the practice of design will be central to the education of the next generation of engineers" (Yellowley, 2001).

CDEN/RCCI had approximately a million dollars that was allocated equally between the formation of individual network nodes at each school, the development and improvement of specific modules and the development of specific high level design competencies through research. (The so-called Design Focus Groups which are the last part of the process)

To try to maintain a modular structure CDEN/RCCI has developed the three-tier approach to design education materials shown in Figure 2. Tier I is concerned with basic sciences, mathematics and engineering sciences. These scientific and mathematical principles are the foundations of engineering design. Tier II builds on Tier I and provides the technologies and engineering practices necessary for Tier III. Tier III deals with open-ended design projects and case studies.

For each tier, there are a number of modules, some of which are discipline specific and the others are common to all engineering programs. Design educators across Canada have been invited to develop and contribute their design education materials under the three-tier system. The modules along with the tier structure, that will be made available on the CDEN/RCCI server, provide sufficient flexibility for design educators to assemble modules for their specific design education needs. It is expected that some of the modules will be available in early 2005 . 


\subsection{Summary}

The paper examines the main issues and challenges that engineering education will face in the near future. The authors propose the use of a Design Directed Engineering approach to integrate new course material and formats in a manner that encourages the most positive overall education experience. This is a very preliminary attempt to stimulate a broad discussion on the future of engineering education. It is our hope that the ideas proposed go some distance towards the development of Programs that use Design as the major vehicle to integrate the tools of engineering science with technology practice and communication skills.

\subsection{References:}

1. Yellowley, I., (2001), "Engineering Design: an Essential Component of University Based Research and Education," Proc of CSME Design
Conference, November 21-22, 2001, Montreal, Canada, Keynote Paper (available at www.cden.ca).

2. Design Chair Group,(2004), "Engineering Design Competency," Final Report.(A condensed version is available as: Stuart, $\mathrm{P}$. et al "Engineering Design Competency", Proceedings Inaugral CDEN/RCCI Conference, Montreal, 2004.

3. Proulx, D.,(2001), The Design Experience at Université de Sherbrooke, Canadian Conference on Engineering Education, Victoria

4. Bright A., Phillips J.R. (1999), "The Harvey Mudd Engineering Clinic Past, Present and Future", Journal of Engineering Education, April1999, pp. 189-194

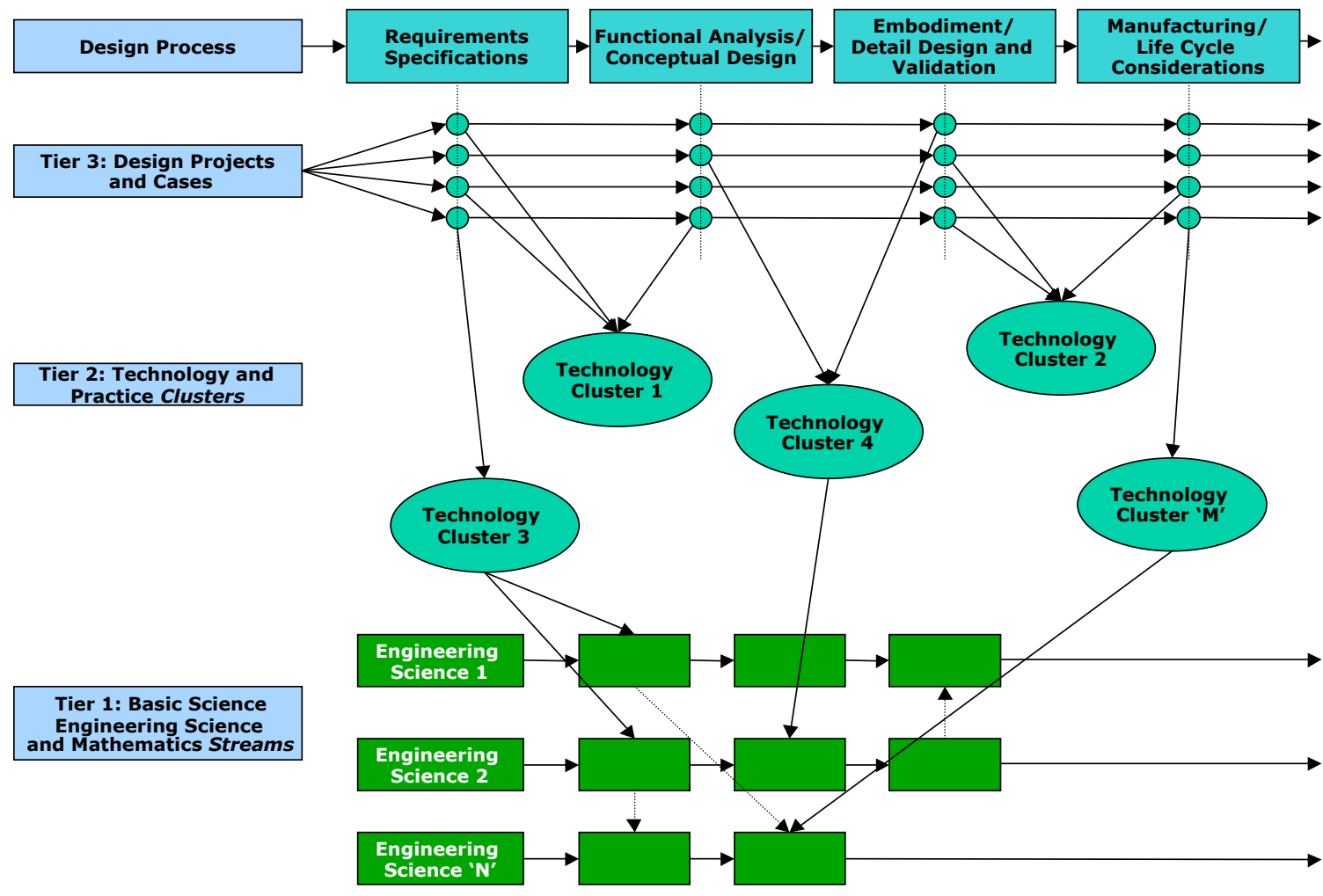

Figure 3. Three-Tier Structure of CDEN/RCCI Design Education Material 